\title{
Colonoscopy Procedure Time: Does the Learning Environment Matter?
}

Jain and colleagues pushed boundaries in their study by focusing on colonoscopy procedure time and the factors that may influence this. ${ }^{1}$ Two of these factors included the level of experience of the endoscopist and the time of day with procedures performed in the afternoon associated with poorer outcomes.

As a medical educationalist and gastroenterologist, I want to share scholarship with the academic community regarding current movements allied to the learning environment. Research is now emerging on the learning space in question to enhance competency. ${ }^{2}$ Many case studies have indicated the value added in ensuring that the learning environment promotes appropriate engagement between learners and mentors, with workspaces that are technology specific to learning complimented with flipped learning approaches, team-based interactions, debriefing rooms, inter-professional discussions, writing spaces, and so on. This also has implications on the physical construct, with alterations in seating design to ensure this is optimized.

The learning environment is a novel element to competency and, from a gastroenterologist's perspective, is an often-overlooked facet. Research on the endoscopy center environment and its physicality may have relevance in endoscopy procedure performance and efficiency. Further work is needed in this regard.

Conflicts of Interest

The author has no financial conflicts of interest.

Neel Sharma ${ }^{1,2}$

${ }^{1}$ Department of Gastroenterology, National University Health System, Singapore, ${ }^{2}$ Harvard Macy Institute, Boston, MA, USA

\section{REFERENCES}

1. Jain D, Goyal A, Zavala S. Predicting colonoscopy time: a quality improvement initiative. Clin Endosc 2016;49:555-559.

2. Nordquist J, Sundberg K, Laing A. Aligning physical learning spaces with the curriculum: AMEE guide No. 107. Med Teach 2016;38:755-768.

Received: September 3, 2016 Accepted: November 2, 2016

Correspondence: Neel Sharma

Department of Gastroenterology, National University Health System, 1E Kent Ridge Road, 119228, Singapore

Tel: +65-9174-5985, Fax: +65-9174-5985, E-mail: sharma_neel@outlook.com

(c) This is an Open Access article distributed under the terms of the Creative Commons Attribution Non-Commercial License (http://creativecommons.org/licenses/by$\mathrm{nc} / 3.0$ ) which permits unrestricted non-commercial use, distribution, and reproduction in any medium, provided the original work is properly cited. 